\title{
Advances in Control of Onion Thrips (Thysanoptera: Thripidae) in Cabbage
}

\author{
A. M. SHELTON, ${ }^{1}$ J. PLATE, and M. CHEN \\ Department of Entomology, New York State Agricultural Experiment Station, Cornell University, \\ 630 W. North Street, Geneva, NY 14456
}

J. Econ. Entomol. 101(2): 438-443 (2008)

\begin{abstract}
Onion thrips, Thrips tabaci Lindeman (Thysanoptera: Thripidae), feeding injury results in discoloration and a rough texture on cabbage, Brassica oleracea capitata (L.), leaves, and damage may occur deep inside the head. It has become a key pest of cabbage in the United States and many other countries. Previous studies have indicated poor control using insecticides. The present study identified imidacloprid drenches and sprays of acetamiprid, dimethoate, spinosad, and imidacloprid as insecticides that performed better than the industry standard, lambda-cyhalothrin. However, additional tests with foliar sprays of dimethoate and acetamiprid indicated there was not an ideal crop stage (precupping, cupping, or postcupping) at which either insecticide could be applied for reliable control of T. tabaci, possibly because of multiple flights of thrips into the crop or the asynchrony of flights and susceptible crop stages. In tests in a commercial field, a soil drench of imidacloprid $4 \mathrm{wk}$ after transplanting reduced the number of damaged leaves in the head by $32 \%$, whereas five sprays of acetamiprid reduced damage by $51 \%$. Combining both insecticide regimes reduced damage by $85 \%$, but resulted in a very costly management program. Cabbage varieties varied considerably in susceptibility with some having negligible thrips injury, regardless of being treated with an insecticide. Planting date affected susceptibility of cabbage to some degree, but not as much as other tactics. Overall, these studies indicate that increased emphasis should be placed on breeding cabbages to be resistant to $T$. tabaci as the foundation for its management.
\end{abstract}

KEY WORDS onion thrips, Thrips tabaci, cabbage, insecticide, plant resistance

Onion thrips, Thrips tabaci Lindeman (Thysanoptera: Thripidae), has become a consistent and severe pest of cabbage, Brassica oleracea capitata (L.), in the United States and many other parts of the world (Shelton et al. 1998, Zezlina and Blazic 2003). It is the only thrips species that we have seen causing damage to cabbage in New York (North and Shelton 1986a). T. tabaci feed on the leaves and cause a bronze color and rough texture on white cabbage and white bumps on red cabbage. When injury is severe on either cabbage type, damage can be observed on the leaves of the outer third of the head (Shelton et al. 1983), and these leaves must be removed before marketing and thus reduce the yield (Hoy and Kretchman 1991). Prevention of damage has primarily focused on host plant resistance and use of insecticides. Although the mechanism(s) of resistance is unknown (Shelton et al. 1988; Stoner and Shelton 1988 a,b,c; Stoner et al. 1989), the use of tolerant varieties has been promoted by extension services (e.g., Reiners and Petzoldt 2006), but thrips-tolerant varieties are not available for all markets (i.e., fresh, processing, and kraut). Thrips are generally not a concern in kraut cabbage because their

${ }^{1}$ Corresponding author, e-mail: ams5@cornell.edu. injury is masked by processing, and there is a defect action threshold that is unlikely to be exceeded, unless populations become very high or the raw product is inspected by kosher standards (Shelton et al. 1982). Additionally, growers or their buyers may choose thrips-susceptible varieties because of other desired characteristics (e.g., head size, color, dry matter content, date of maturity, and storagability) and then use supplemental methods for control. Often they have been disappointed with the lack of effective supplemental methods. In seven insecticide trials conducted from 1987 to 1996, using a total of 17 different insecticides, insecticide applications reduced thrips damage in only two of the trials (Shelton et al. 1998). Furthermore, in highly susceptible varieties, we concluded that even the frequent application of insecticides was not sufficient to keep thrips damage at acceptable levels.

T. tabaci have continued to be problematic in commercial cabbage production in New York and elsewhere, especially when less tolerant varieties have been used and during hot, dry years when more generations of thrips are produced and there is less natural mortality to them from rainfall. Since our previous study (Shelton et al. 1998), newer insecticides have 
come onto the market with characteristics that may be helpful for thrips management (e.g., increased systemic activity and reduced toxicity to natural enemies of thrips). However, some of these materials are more costly than the commonly used pyrethroids that many growers use as the mainstay for controlling the complex of insects, including T. tabaci, on cabbage. Therefore, it is even more important to determine whether the number of applications could be reduced through better timing of insecticide application or modification of planting dates.

The purpose of this study was to evaluate control of T. tabaci on cabbage by using insecticides and timing of treatments, and also to document susceptibility of newer cabbage varieties and determine whether damage could be reduced by altering the time of planting.

\section{Materials and Methods}

General Procedures. Experiments were conducted in 2003 and 2004 in Cornell's Fruit and Vegetable Research Farm (CFVRF) near Geneva, NY, and a nearby commercial farm in the cabbage growing area of upstate New York where T. tabaci is a key pest. All trials were conducted using commercial varieties of cabbage and natural populations of T. tabaci. Depending on the trial, the following insecticides were used: imidacloprid, drench application (Admire $2 \mathrm{~F}$ ) and foliar application (Provado 1.6 F) (Bayer CropScience, Research Park Triangle, NC); acetamiprid, foliar spray (Assail 70 WP, Cerexagri-Nisso, LLC, King of Prussia, PA); dimethoate, foliar spray (Dimethoate 400, UAP-Northeast, Fancher, NY); spinosad, foliar spray (Spintor 2CS, Dow AgroSciences, Indianapolis, IN); and lambda-cyhalothrin, foliar spray (Warrior T, Syngenta Crop Protection, Inc., Greensboro, NC). A $\mathrm{CO}_{2}$ backpack sprayer was used for application of foliar treatments and consisted of a one-row boom with three nozzles per row (one nozzle over the top and one drop nozzle on each side) with TeeJet XR8002VS nozzles delivering 282 liters/ha at $2.8 \mathrm{~kg} /$ $\mathrm{cm}^{2}$ at a speed of $6.44 \mathrm{~km} / \mathrm{h}$. Although most growers do not use drop nozzles, they provide better coverage and control and would more readily enhance treatment differences. All trials conducted at CFVRF and the commercial farm used 76 -cm between-row spacing and $45-\mathrm{cm}$ in-row plant spacing. Thrips damage in all trials was assessed at harvest by randomly selecting a set number of heads in a replicate and counting the number of leaf layers (out of the top 10 layers) on each head that had typical thrips injury as described above. Previous research had indicated that this quantitative measure of thrips damage compared favorably to a more qualitative measure of damage ratings that emphasized the visible amount of injury to each layer (Shelton et al. 1983), and we have used the number of layers damaged at harvest as our standard method of evaluation. To compare treatments, we used the average number of damaged layers per head in a replicate and then analyzed these averages using the General Linear model (GLM) procedure and Fisher protected least significant difference (LSD) mean separation test. All statistical calculations were performed using the SPSS package (version 11.5 for Windows, SPSS Inc., Chicago, IL).

Multiple Insecticides Trial, 2003. 'Carlton' cabbage (Seedway, Hall, NY), a thrips-susceptible variety, was transplanted on 27 June at CFVRF. Plots consisted of three rows with the treated row in the middle and blocks were replicated three times in a randomized complete block (RCB) design. Blocks consisted of seventeen rows $9.14 \mathrm{~m}$ in length. The imidacloprid treatment consisted of three applications applied as a drench at $2 \mathrm{wk}$ (18 July), $4 \mathrm{wk}$ (31 July), and $6 \mathrm{wk}$ ( 15 August) posttransplanting. Three applications of imidacloprid would not be an economical grower practice but was used to determine whether any control could be obtained with this product. All foliar treatments were applied weekly from 18 July to 26 September (excluding the week of 3-9 August due to heavy precipitation [average daily precipitation from 3 to 9 August was $12.2 \mathrm{~mm}$ ]). Harvest evaluations for thrips damage were made on 2 October by randomly selecting three heads per plot and assessing damage as noted above.

Timing of Dimethoate (2003) and Acetamiprid (2004) Spray Trials. Carlton cabbage was transplanted on 3 July 2003 at CFVRF. Plots consisted of three rows with the treated row in the middle and blocks were replicated three times in a RCB design. Blocks consisted of seventeen rows $9.14 \mathrm{~m}$ in length. Dimethoate at $493.0 \mathrm{~g} \mathrm{(AI)} \mathrm{/} \mathrm{ha} \mathrm{was} \mathrm{the} \mathrm{only} \mathrm{insecticide} \mathrm{used} \mathrm{in} \mathrm{this}$ study and was applied as a foliar spray to specific rows when the cabbage was in a specific crop stage: precupping, cupping, and the postcupping (Andaloro et al. 1983). Eight treatments were used based on these stages and combinations of these stages, plus an untreated control. Treatments began 2 wk posttransplanting, and each crop stage consisted of a 3-wk period: precupping treatments were applied on 18, 25, and 31 July; cupping treatments were applied on 15, 25 , and 29 August; and postcupping sprays were applied on 8, 17, and 26 September. No sprays were applied the week of 3-9 August for the reasons described above. Harvest evaluations for thrips damage were made on 3 October as described previously. Data were analyzed as described above.

A trial conducted in 2004 was similar to the trial conducted with dimethoate in 2003 , but used acetamiprid because of its good performance in 2003 (Table 1). 'Rinda' cabbage (Petoseed, Saticoy, CA), a thrips-susceptible variety, was transplanted on 8 June 2004 at CFVRF. Plots consisted of three rows with the treated row in the middle and blocks were replicated six times in an RCB design. Blocks consisted of seventeen rows $9.14 \mathrm{~m}$ in length. Acetamiprid at $78.4 \mathrm{~g}$ (AI) / ha was the only insecticide used in this study and was applied as a foliar spray to specific rows when the cabbage was in a specific crop stage. Treatments began at $2 \mathrm{wk}$ posttransplanting, and each crop stage consisted of a 4-wk time period: precupping treatments were applied on 23 and 30 June and 8 and 14 July; cupping treatments were applied on 21 and 29 July, 4 and 11 August; and postcupping sprays were applied 
Table 1. Effect of different insecticides on T. tabaci injury to cabbage, Geneva, NY, 2003

\begin{tabular}{lcc}
\hline \multicolumn{1}{c}{ Treatment $^{a}$} & Rate $(\mathrm{g}[\mathrm{AI}] / \mathrm{ha})$ & $\begin{array}{c}\text { Mean no. layers } \\
\text { damaged }^{b, c}\end{array}$ \\
\hline Acetamiprid & 168.1 & $0.8 \pm 0.3 \mathrm{a}$ \\
Imidacloprid drench & 313.7 & $1.4 \pm 0.2 \mathrm{ab}$ \\
Spinosad & 145.7 & $2.0 \pm 0.3 \mathrm{bc}$ \\
Imidacloprid spray & 56.0 & $2.1 \pm 0.3 \mathrm{bc}$ \\
Acetamiprid & 78.4 & $2.1 \pm 0.4 \mathrm{bc}$ \\
Dimethoate & 493.0 & $2.4 \pm 0.2 \mathrm{c}$ \\
Lamdba-Cyhalothrin $^{d}$ & 28.0 & $3.3 \pm 0.3 \mathrm{~d}$ \\
Untreated control $^{\text {Und }}$ & & $5.0 \pm 0.4 \mathrm{e}$ \\
\hline
\end{tabular}

\footnotetext{
${ }^{a}$ See text for treatment frequencies.

${ }^{b}$ Based on examination of the top 10 layers of cabbage leaves in the head.

${ }^{c}$ Means $\pm \mathrm{SE}$ within a column followed by different lowercase letters are significantly different $(P<0.05$; Fisher's protected LSD). ${ }^{d}$ Industry standard.
}

on 17 and 24 August and 2 and 8 September. Harvest evaluations for thrips damage were made on 16 September. Data were analyzed as described above.

Planting Date $\times$ Variety $\times$ Dimethoate Trial, 2003. The effect of insecticide treatment, planting date, and variety were evaluated for their effects on thrips injury by using a split-split plot design. This trial was conducted because of frequent control failures with lambda-cyhalothrin, the only product labeled in New York at that time for thrips control on cabbage. Previous studies had shown dimethoate to be more effective than lambda-cyhalothrin (A.M.S., unpublished data), and newer varieties of cabbages were being promoted by seed companies. Furthermore, some growers were altering their planting dates in hope of reducing thrips damage. Fifteen varieties of cabbage were selected based on their relative susceptibility to thrips in previous trails (A.M.S., unpublished data). The varieties were evaluated using two planting dates (11 and 24 July) with each variety at each planting date also being treated or not treated with an insecticide. Cabbages were transplanted as described above at CFVRF. Each subplot consisted of a single row of a single variety of cabbage, $9.14 \mathrm{~m}$ in length, and blocks consisted of two main plots, each with 15 rows of cabbage, replicated four times. All plants were treated with a Bacillus thuringiensis variety kurstaki product for control of Lepidoptera, as needed. One main plot (15 of 30 rows) in each block was treated with foliar sprays of dimethoate at $493.0 \mathrm{~g}$ (AI) / ha for thrips. Applications of dimethoate were made weekly from 18 July to 10 October, excluding only the week of 3-9 August for the reasons described above. Harvest evaluations for thrips damage were made when individual varieties reached maturity by randomly selecting five heads per row, and evaluating them as described above. Data were analyzed as described above but using a GLM procedure with insecticide as the whole plot treatment, planting date as the split plot, and cabbage variety as the split-split plot.

Commercial Field Insecticide Trial, 2004. Rinda cabbage was transplanted on 7 May in a commercial field near Geneva, NY. Plots consisted of eight rows,
Table 2. Effect of timing sprays of dimethoate (2003) or acetamiprid (2004) on T. tabaci injury to cabbage, Geneva, NY

\begin{tabular}{llc}
\hline \multirow{2}{*}{ Time of spray application $^{a}$} & \multicolumn{2}{c}{ Mean no. layers damaged ${ }^{b, c}$} \\
\cline { 2 - 3 } & Dimethoate & Acetamiprid \\
\hline Precupping only & $1.8 \pm 0.2 \mathrm{a}$ & $3.1 \pm 0.4 \mathrm{c}$ \\
Precupping and cupping & $2.3 \pm 0.3 \mathrm{ab}$ & $2.4 \pm 0.3 \mathrm{bc}$ \\
Precupping and postcupping & $3.9 \pm 0.3 \mathrm{c}$ & $2.0 \pm 0.5 \mathrm{ab}$ \\
Cupping only & $2.0 \pm 0.4 \mathrm{a}$ & $1.8 \pm 0.4 \mathrm{ab}$ \\
Cupping and postcupping & $2.0 \pm 0.6 \mathrm{a}$ & $1.1 \pm 0.1 \mathrm{a}$ \\
Postcupping only & $2.9 \pm 0.2 \mathrm{~b}$ & $1.4 \pm 0.1 \mathrm{a}$ \\
All stages (weekly) & $2.1 \pm 0.3 \mathrm{ab}$ & $1.3 \pm 0.2 \mathrm{a}$ \\
Untreated control & $5.0 \pm 0.4 \mathrm{~d}$ & $4.7 \pm 0.4 \mathrm{~d}$ \\
\hline
\end{tabular}

${ }^{a}$ See text for treatment frequencies. Dimethoate was applied at $493 \mathrm{~g}$ (AI) / ha and acetamiprid applied at $78.4 \mathrm{~g}$ (AI)/ ha.

${ }^{b}$ Based on examination of the top 10 layers of cabbage leaves in the head.

Means \pm SE within a column followed by different lowercase letters are significantly different $(P<0.05$; Fisher's protected LSD).

including an untreated row on each side, $6.1 \mathrm{~m}$ in length. Blocks were replicated three times in a RCB design. Because the 2003 trial with three applications of imidacloprid as a drench (Table 1) demonstrated the material was effective, the next step was to determine if a single application would be sufficient. The imidacloprid treatment consisted of a single application applied $4 \mathrm{wk}$ after transplanting on 7 June and was applied by the grower with the side dressing of fertilizer. Foliar sprays were applied by us with the $\mathrm{CO}_{2}$ backpack sprayer, described above. Sprays of acetamiprid at $78.4 \mathrm{~g}(\mathrm{AI}) /$ ha were applied at $6,7,8,11$, and 12 wk after transplanting. Rain prevented applications during week 9 and 10. Harvest evaluations for thrips damage were made on 4 August by randomly selecting 12 heads per plot, and examining them as described above. Data were analyzed as described above.

\section{Results}

Multiple Insecticides Trial, 2003. All treatments had significantly fewer layers damaged compared with the untreated control $(F=19.018$, df $=7, P<0.001)$ (Table 1). The treatment with acetamiprid at $168.1 \mathrm{~g}$ (AI) / ha (a high test rate) showed the least amount of thrips injury and was significantly better than all other treatments except imidacloprid applied as a drench. The two registered (as of 2003) treatments (dimethoate and lambda-cyhalothrin) showed significantly less damage than the untreated control but significantly more damage than acetamiprid at $168 \mathrm{~g}$ (AI) / ha and the drench of imidacloprid. The dimethoate and acetamiprid at $78.4 \mathrm{~g}$ (AI) / ha (an eventually registered rate) treatments were significantly better than lambda-cyhalothrin.

Timing of Dimethoate (2003) and Acetamiprid (2004) Spray Trials. In 2003 when dimethoate was used, all treatments had significantly fewer layers damaged compared with the untreated control ( $F=$ 10.289, $\mathrm{df}=7, P<0.001$ ) (Table 2). Although there were significant differences between some treatments, there was no statistically valid indication that applying dimethoate at any single stage, or multiple 
Table 3. Susceptibility of cabbage varieties to T. tabaci damage as affected by sprays of dimethoate and planting date, Geneva, NY, 2003

\begin{tabular}{|c|c|c|c|c|}
\hline \multirow{3}{*}{ Variety $^{a}$} & \multicolumn{4}{|c|}{ Mean no. layers damaged ${ }^{b, c}$} \\
\hline & \multicolumn{2}{|c|}{ First planting (3 July 2003) } & \multicolumn{2}{|c|}{ Second planting (25 July 2003) } \\
\hline & Sprayed $^{d}$ & Not sprayed & Sprayed $^{d}$ & Not sprayed \\
\hline Amtrak & $1.0 \pm 0.2 \mathrm{aABCD}$ & $1.5 \pm 0.2 \mathrm{aABC}$ & $1.0 \pm 0.3 \mathrm{aBC}$ & $1.8 \pm 0.1 \mathrm{bDEFG}$ \\
\hline Autoro & $2.6 \pm 0.4 \mathrm{aF}$ & $2.5 \pm 0.6 \mathrm{aCD}$ & $0.4 \pm 0.2 \mathrm{aAB}$ & $1.2 \pm 0.2 \mathrm{aBCD}$ \\
\hline Bobcat & $0.7 \pm 0.3 \mathrm{aAB}$ & $0.6 \pm 0.3 \mathrm{aA}$ & $1.7 \pm 0.2 \mathrm{aDE}$ & $2.2 \pm 0.2 \mathrm{aFG}$ \\
\hline Bronco & $1.4 \pm 0.2 \mathrm{aBCDE}$ & $2.0 \pm 0.3 \mathrm{aBCD}$ & $2.3 \pm 0.2 \mathrm{aEF}$ & $1.8 \pm 0.3 \mathrm{aDEFG}$ \\
\hline Cairo & $1.9 \pm 0.3 \mathrm{aCDEF}$ & $1.3 \pm 0.2 \mathrm{aAB}$ & $0.2 \pm 0.1 \mathrm{aA}$ & $0.2 \pm 0.1 \mathrm{aA}$ \\
\hline Cecile & $4.7 \pm 0.8 \mathrm{aG}$ & $3.8 \pm 0.4 \mathrm{aE}$ & $1.7 \pm 0.2 \mathrm{aDE}$ & $1.9 \pm 0.3 \mathrm{aEFG}$ \\
\hline Fresco & $1.0 \pm 0.3 \mathrm{aABCD}$ & $1.4 \pm 0.3 \mathrm{aAB}$ & $2.4 \pm 0.2 \mathrm{aF}$ & $2.0 \pm 0.2 \mathrm{aFG}$ \\
\hline HMX 0222 & $2.4 \pm 0.2 \mathrm{aEF}$ & $3.8 \pm 0.2 \mathrm{bE}$ & $1.2 \pm 0.2 \mathrm{aCD}$ & $1.9 \pm 0.2 \mathrm{bEFG}$ \\
\hline Huron & $0.9 \pm 0.3 \mathrm{aABC}$ & $2.5 \pm 0.3 \mathrm{bCD}$ & $2.6 \pm 0.3 \mathrm{aF}$ & $2.3 \pm 0.2 \mathrm{aG}$ \\
\hline Megaton & $4.6 \pm 0.6 \mathrm{aG}$ & $3.7 \pm 0.2 \mathrm{aE}$ & $0.8 \pm 0.3 \mathrm{aABC}$ & $1.7 \pm 0.3 \mathrm{bDEF}$ \\
\hline Mentor & $1.6 \pm 0.2 \mathrm{aBCDEF}$ & $1.8 \pm 0.2 \mathrm{aBCD}$ & $0.9 \pm 0.2 \mathrm{aBC}$ & $0.6 \pm 0.2 \mathrm{aAB}$ \\
\hline Missouri & $0.3 \pm 0.2 \mathrm{aA}$ & $1.3 \pm 0.2 \mathrm{aAB}$ & $0.6 \pm 0.2 \mathrm{aABC}$ & $0.7 \pm 0.2 \mathrm{aABC}$ \\
\hline Moreton & $4.4 \pm 0.4 \mathrm{bG}$ & $2.8 \pm 0.7 \mathrm{aDE}$ & $0.7 \pm 0.2 \mathrm{aABC}$ & $1.4 \pm 0.2 \mathrm{bDE}$ \\
\hline Rinda & $6.0 \pm 0.6 \mathrm{aH}$ & $7.2 \pm 0.6 \mathrm{bF}$ & $2.9 \pm 0.4 \mathrm{aF}$ & $3.5 \pm 0.2 \mathrm{bH}$ \\
\hline Transam & $2.0 \pm 0.3 \mathrm{aDEF}$ & $1.8 \pm 0.2 \mathrm{aBCD}$ & $1.2 \pm 0.2 \mathrm{aCD}$ & $1.2 \pm 0.2 \mathrm{aCD}$ \\
\hline
\end{tabular}

${ }^{a}$ Seed sources: Bejo Seeds (Amtrak, Autoro, Bronco, Cecile, Fresco, Megaton, Mentor, Transam), Harris Moran (HMX 0222), Petoseeds (Rinda), Reed's Seeds (Bobcat, Moreton), Seedway (Cairo), and Seminis (Missouri).

${ }^{b}$ Based on examination of the top 10 layers of cabbage leaves in the head.

${ }^{c}$ Means \pm SE followed by different lowercase letters within a row for each planting date or followed by different capital letters within a column are significantly different $(P<0.05$; Fisher's protected LSD).

${ }^{d}$ See text for treatment frequencies. Dimethoate applied at $493 \mathrm{~g}$ (AI)/ ha.

stages, was preferable to any other stage or combination of stages. For example, spraying only during the precupping period resulted in only 1.8 layers injured, but adding sprays at the postcupping stage resulted in 3.9 layers injured.

In 2004 when acetamiprid was used, all treatments had significantly fewer layers damaged compared with the untreated control $(F=12.602, \mathrm{df}=7, P<0.001)$ (Table 2). As in 2003 when dimethoate was used (Table 2), there were significant differences between some treatments, but there was no statistically valid indication that applying the insecticide at any single stage, or multiple stages, was preferable to any other stage or combination of stages. For example, spraying only during the postcupping period resulted in 1.4 layers injured, which was statistically similar to sprays applied at the cupping period (1.8 layers injured) . However, when sprays were applied at both periods the mean number of layers damaged was 1.1 which, although not statistically different from spraying at either time period, indicates it is difficult to predict the optimal crop stage when sprays should be applied.

Planting Date $\times$ Variety $\times$ Dimethoate Trial, 2003. Thrips damage was significantly affected by variety $(F=17.775, \mathrm{df}=14, P<0.001)$ and planting date $(F=$ $64.193, \mathrm{df}=1, P<0.001$ ), but spraying dimethoate did not have a significant effect on reducing thrips damage across all varieties $(F=3.496, \mathrm{df}=1, P=0.067)$ (Table $3)$. Variety had the most dramatic effect as illustrated by the 'Bobcat', which sustained little damage $(\leq 2.2$ layers injured) regardless of planting date or being treated with foliar sprays of dimethoate. In contrast, in the first planting Rinda had 7.2 layers injured in the nonsprayed plots and 6.0 layers in sprayed plots. The interactions of spray and planting date $(F=0.27, \mathrm{df}=$ $1, P=0.605)$; spray and variety $(F=1.223, \mathrm{df}=14, P=$
$0.285)$; or spray, variety, and planting date $(F=1.447$, $\mathrm{df}=14, P=0.162$ ) did not significantly affect damage, except for the interactions between variety and planting date $(F=10.607, \mathrm{df}=14, P<0.001)$. Planting date generally had little effect on the more tolerant varieties. Unlike in our previous study (Shelton et al. 1998), damage was less severe in the later planting. This may have been due to reduced immigration of thrips into cabbage from other crops (North and Shelton 1986b) or increased mortality from the abundant rainfall.

Commercial Field Insecticide Trial, 2004. All treatments had significantly fewer layers damaged compared with the untreated control $(F=41.038, \mathrm{df}=3$, $P<0.001$ ) (Table 4). Acetamiprid alone reduced the mean number of damaged layers from 7.1 to 3.5 (51\% reduction), whereas imidacloprid alone reduced the layers damaged to 4.8 (32\% reduction). Using both insecticides provided better control of thrips damage than either material alone and reduced the layers

Table 4. Effect of imidacloprid and acetamiprid alone and in combination on $T$. tabaci injury to cabbage in a commercial field near Geneva, NY, 2004

\begin{tabular}{lcc}
\hline \multicolumn{1}{c}{ Treatment $^{a}$} & Rate $(\mathrm{g}[\mathrm{AI}] / \mathrm{ha})$ & $\begin{array}{c}\text { Mean no. layers } \\
\text { damaged }^{b, c}\end{array}$ \\
\hline $\begin{array}{l}\text { Imidacloprid drench } \\
+5 \text { acetamiprid sprays }\end{array}$ & $313.7+78.4$ & $1.1 \pm 0.2 \mathrm{a}$ \\
$\begin{array}{l}\text { Five acetamiprid sprays } \\
\text { Imidacloprid drench }\end{array}$ & 78.4 & $3.5 \pm 0.2 \mathrm{~b}$ \\
Untreated control & 313.7 & $4.8 \pm 0.3 \mathrm{c}$ \\
\hline
\end{tabular}

${ }^{a}$ See text for treatment frequencies.

${ }^{b}$ Based on examination of the top 10 layers of cabbage leaves in the head.

${ }^{c}$ Means \pm SE within a column followed by different lowercase letters are significantly different $(P<0.05$; Fisher's protected LSD). 
damaged from 7.1 in the control to 1.1 ( $85 \%$ reduction) (Table 4).

\section{Discussion}

These results emphasize the value of using thripsresistant cabbage varieties as the foundation for thrips management. Growers and researchers can obtain a list of many commercial cabbage varieties and their susceptibility to thrips under New York conditions (Reiners and Petzoldt 2006). If resistant varieties are not used, we have found some insecticides that can reduce thrips damage much more effectively than in our previous studies (Shelton et al. 1998). Our 2003 studies identified imidacloprid drenches and sprays of acetamiprid, dimethoate, spinosad and imidacloprid as insecticides that performed better than the industry standard, lambdacyhalothrin (Table 1), although they are considerably more expensive. However, further tests with foliar sprays of dimethoate and acetamiprid (Table 2 ) indicated there was not an ideal crop stage at which either insecticide could be applied for reliable control of T. tabaci. In our 2004 tests with acetamiprid, if only one crop stage were to be sprayed, our results suggest that the cupping and postcupping period may be preferable. However, this was not true in our 2003 trial with dimethoate. Additionally, we are puzzled by sometimes having increased injury with increased frequency of sprays as was the case in 2003 when applications of dimethoate at the precupping stage resulted in lower injury than when applications were made at the precupping and postcupping stages. Although we do not have any explanation, several hypotheses can be stated including that sprays might have driven thrips deeper into the head, killed natural enemies that were suppressing thrips, or increased the fecundity of thrips.

Because T. tabaci move into cabbage from various field crops when they are no longer suitable habitats (North and Shelton 1986a,b; Shelton and North 1986), there may be multiple flights that colonize cabbage and such flights are difficult to predict on a field-byfield basis. Altering the planting date does not seem to be a reliable tactic for reducing thrips injury because our 2003 results differed from those obtained in our earlier study (Shelton et al. 1998). Furthermore, temperatures influences thrips flights, and it may or may not cause them to align with particular phenological stages of cabbage (further complexity is added because of the many commercial cabbage varieties that vary in time to maturity from $\approx 75$ to over $125 \mathrm{~d}$ ). Hence, it does not seem practical to recommend spray applications based on plant growth stages alone (Table 2). However, an imidacloprid drench applied soon after transplanting can be taken up by the plant and reduce the amount of injury at harvest (Tables 1 and 4 ). We did not investigate how much imidacloprid would be in the plant at any particular plant stage, or what the minimum required dose of the insecticide would be for T. tabaci. It is likely that the amount of insecticide in the plant would vary depending on soil moisture and soil type, so it may be difficult to predict the level of control that could be obtained under diverse environmental conditions. Results from the test conducted in a commercial field (Table 4) documented that an imidacloprid drench applied four wks after transplanting provided an early season control that had to be supplemented with five additional sprays of acetamiprid. At the current product prices, this will be an expensive program because the imidacloprid treatment would cost $\$ 221.20 /$ ha, and each spray of acetamiprid would costs $\$ 50.40 /$ ha, making a total insecticide program for thrips control of $\$ 473.20$ / ha. Furthermore, using imidacloprid would be an early season prophylactic measure that may not be cost effective in a cool, wet year when thrips populations would likely be reduced by weather, but such environmental conditions are difficult to predict. Thus, use of foliar sprays of acetamiprid may be more economical, but the present registration of this product would not allow the number of sprays needed for control. With the use of both products there could be concern about the evolution of resistance because both products are in the same insecticide class (neonicotinoid). However, the evolution of resistance would likely be slowed because it seems that once thrips are in a cabbage head, they and their offspring are unlikely to be able to leave the head to spread their resistance alleles before harvest (A.M.S., unpublished data). Still, management of thrips in cabbage using insecticides is an expensive approach and additional costs for insecticides could be avoided if more thrips-tolerant varieties were available that would satisfy the needs of the producer and buyer. We strongly suggest that breeders increase efforts to produce thrips-tolerant cabbage varieties for the diversity of the cabbage markets (i.e., fresh, processing, and storage cabbages).

\section{Acknowledgments}

We are grateful to the companies that supplied the insecticides and to E. Hansen for allowing us to work in private cabbage fields.

\section{References Cited}

Andaloro, J. T., K. B. Rose, A. M. Shelton, C. W. Hoy, and R. F. Becker. 1983. Cabbage growth stages. N.Y. Food Life Sci. Bull. 101.

Hoy, C. W., and D. W. Kretchman. 1991. Thrips (Thysanoptera: Thripidae) injury to cabbage cultivars in Ohio. J. Econ. Entomol. 84: 971-977.

North, R. C., and A. M. Shelton. 1986a. Colonization and intraplant distribution of Thrips tabaci on cabbage. J. Econ. Entomol. 79: 219-223.

North, R. C., and A. M. Shelton. 1986b. Ecology of Thysanoptera within cabbage fields. Environ. Entomol. 15:520-526.

Reiners, S., and C. H. Petzoldt. 2006. Integrated crop and pest management guidelines for commercial vegetable production. (http://www.nysaes.cornell.edu/recommends/).

Shelton, A. M., R. F. Becker, and J. T. Andaloro. 1983. Varietal resistance to onion thrips in processing cabbage. J. Econ. Entomol. 76: 85-86. 
Shelton, A. M., and R. C. North. 1986. Species composition and phenology of Thysanoptera within field crops adjacent to cabbage fields. Environ. Entomol. 15: 513519.

Shelton, A. M., C. W. Hoy, R. C. North, M. H. Dickson, and J. Barnard. 1988. Analysis of resistance in cabbage varieties to damage by Lepidoptera and Thysanoptera. J. Econ. Entomol. 81: 634-640.

Shelton, A. M., J. R. Stamer, W. T. Wilsey, B. O. Stoyla, and J. T. Andaloro. 1982. Onion thrips damage and contamination in sauerkraut. J. Econ. Entomol. 75: 492-494.

Shelton, A. M., W. T. Wilsey, and M. A. Schmaedick. 1998. Management of onion thrips on cabbage using plant resistance and insecticides. J. Econ. Entomol. 91: 329333.

Stoner, K. A., and A. M. Shelton. 1988a. Role of nonpreference in the resistance of cabbage varieties to the onion thrips (Thysanoptera: Thripidae). J. Econ. Entomol. 81: 1062-1067.
Stoner, K. A., and A. M. Shelton. 1988b. Effect of planting date and timing of growth stages on damage to cabbage by onion thrips (Thysanoptera: Thripidae). J. Econ. Entomol. 81: 1186-1189.

Stoner, K. A., and A. M. Shelton. 1988c. Influence of variety on abundance and within-plant distribution of onion thrips (Thysanoptera: Thripidae) on cabbage. J. Econ. Entomol. 81: 1190-1195.

Stoner, K. A., M. H. Dickson, and A. M. Shelton. 1989. Inheritance of resistance to damage by Thrips tabaci Lindeman (Thysanoptera: Thripidae) in cabbage. Euphytica 40: 233-239.

Zezlina, I., and M. Blazic. 2003. Testing the efficacy of different insecticides to control onion thrips (Thrips tabaci Lindeman, Thysanoptera, Thripidae) in onion crops. Commun. Agric. Appl. Biol. Sci. 68: 287-290.

Received 5 July 2007; accepted 6 October 2007. 